Proceeding Paper

\title{
Phytotoxic Effect of Caraway Essential Oil and Its Main Compounds against Germination of Spring Wheat, Wild Oat and Chamomile ${ }^{\dagger}$
}

\author{
Beata Jop $^{1, * \mathbb{D}}$, Anna Wajs-Bonikowska ${ }^{2}$ and Agnieszka Synowiec ${ }^{1}$ (D) \\ 1 Department of Agroecology and Crop Production, University of Agriculture in Krakow, \\ 31-120 Cracow, Poland; a.synowiec@urk.edu.pl \\ 2 Institute of Natural Products and Cosmetics, Lodz University of Technology, 90-924 Lodz, Poland; \\ anna.wajs-bonikowska@p.lodz.pl \\ * Correspondence: beata.jop@urk.edu.pl \\ † Presented at the 1st International Electronic Conference on Agronomy, 3-17 May 2021; Available online: \\ https:/ / sciforum.net/conference/IECAG2021.
}

Citation: Jop, B.; Wajs-Bonikowska, A.; Synowiec, A. Phytotoxic Effect of Caraway Essential Oil and Its Main Compounds against Germination of Spring Wheat, Wild Oat and Chamomile. Biol. Life Sci. Forum 2021, 3, 20. https://doi.org/10.3390/ IECAG2021-09713

Academic Editor: Giuseppe Colla

Published: 1 May 2021

Publisher's Note: MDPI stays neutral with regard to jurisdictional claims in published maps and institutional affiliations.

Copyright: (C) 2021 by the authors. Licensee MDPI, Basel, Switzerland. This article is an open access article distributed under the terms and conditions of the Creative Commons Attribution (CC BY) license (https:// creativecommons.org/licenses/by/ $4.0 /)$.

\begin{abstract}
Caraway oil is a promising botanical herbicide. This study tested the phytotoxic potential of caraway oil, carvone and d-limonene on germination and seedlings' growth of spring wheat, wild oat and chamomile. As a result, an inhibiting effect of caraway oil and carvone on all the tested species was found. Contrary, d-limonene displayed selective toxicity against chamomile and wild oat, which should be investigated further.
\end{abstract}

Keywords: botanical herbicide; carvone; d-limonene; ED50; selective toxicity

\section{Introduction}

Increased interest in the use of biological crop-protection methods has led to research on using the allelopathic potential of various plant species to reduce agricultural pests [1,2]. Essential oils of plant origin show phytotoxic properties that can be used to produce socalled botanical herbicides, i.e., substances of plant origin for weed control [3]. Essential oils as herbicides could be leaf-sprayed [4-6] or soil-applied [7,8]. However, the most frequently analysed effect of the use of essential oils against weeds is their influence on seed germination and the growth of seedlings $[9,10]$. For comparison of the allelopathic potential of the essential oils, the effective dose of the oil, causing a $50 \%$ inhibition of seeds germination (so-called ED50 dose) [11], is being widely applied [9,12].

One of the promising oils for herbicidal application is caraway oil [4]. The yield of essential oil obtained from caraway fruits is in the range of $1-6 \%$. The oil is rich in oxygenated monoterpenes, mainly carvone and d-limonene, constituting up to $95 \%$ of all oil compounds [13].

The biological action of essential oils is attributed to synergistic effects of their compounds, as was found, i.e., for clove oil [5,14]. Our study aimed to investigate the phytotoxic potential of water solutions of caraway oil and its main compounds: carvone and d-limonene, to the germination and initial growth of spring wheat (Triticum aestivum L.), wild oat (Avena fatua L.) and chamomile (Matricaria chamomilla L.).

\section{Material and Methods}

Caraway essential oil (EO) of Polish origin was purchased from the producer HerbaNordPol Sp. z o. o. (Gdansk, PL). The fractionation of the oil and analysis of its composition were carried out at the Institute of Natural Products and Cosmetics, Lodz University of Technology. Under reduced pressure, the essential oil was rectified with a fractional column (Vigerous column, $3 \times 20 \mathrm{~cm}$ ). Next, the collected fractions were analyzed by the GC-MS-FID method on a Trace GC Ultra gas chromatograph connected to a DSQ II mass 
spectrometer (Thermo Electron, Waltham, MA, USA). Simultaneous analysis of GC-FID and MS was performed thanks to the MS-FID splitter (SGE Analytical Science, Ringwood, Vic, Australia). The components of the EO were identified by comparing the experimental retention indexes (RI) of the analysed components with the indexes in the Mass Finder 4.0 library and the NIST MS Search database (2012) and by comparing the mass spectra of the tested compounds with the patterns contained in the computer library Wiley Registry 10th Edition/NIST (2012) Mass Spectral Library.

A Petri dish (11 cm diameter) experiment was carried out in glass dishes, in four series with three repetitions. The essential oil was applied as an oil in water $(0 / w)$ solution, with $5 \%$ acetone as a carrier. Five doses of caraway oil: $0.004 ; 0.007 ; 0.01 ; 0.02 ; 0.03 \mathrm{~g}$ per dish; five doses of carvone: $0.002 ; 0.004 ; 0.008 ; 0.012 ; 0.02 \mathrm{~g}$ per dish and five doses of d-limonene: $0.001 ; 0.002 ; 0.005 ; 0.007 ; 0.01 \mathrm{~g}$ per dish were used. The control treatment was composed of acetone and water only. The doses of EO components, carvone and d-limonene reflected their percentage content in the oil, $60 \%$ and $35 \%$, respectively. The filter paper was soaked with $7 \mathrm{~mL}$ of an appropriate o/w solution of EO or its component. The seeds of spring wheat (T. aestivum L. cv. Tybalt) and weed seeds-wild oats (A. fatua L.) and chamomile (M. chamomilla L.) were used. Mature wild oats seeds were collected from a spring wheat field in southern Poland in 2016. Certified chamomile seeds were purchased (PlantiCo Sp. Z o. o., Krzeszowice, PL). Twenty seeds of the tested species were placed on two layers of sterile filter paper in each dish. The seeds were allowed to germinate for seven days in the dark at room temperature $\left( \pm 25^{\circ} \mathrm{C}\right)$. The seedlings were counted seven days after, and the lengths $[\mathrm{mm}]$ of their roots and shoots were measured.

The percentage of germinated seeds was analysed using dose-response nonlinear analysis ('drc') [11]. Three parameters were used to fit the log-logistic curve $(Y)$ according to [15], where the lower limit is equal to zero:

$$
Y=d /(1+\exp (b(\log x-\log e)))
$$

where $e$ is the ED50 value, $d$ is the upper limit, $b$ denotes the relative slope around $e$ and $x$ is the percentage germination or root/shoot length. The ED50 value was calculated in the ' $d r c$ ' package and further used to compare the phytotoxic effect of the EOs against the tested plants [4]. All statistical analyses were performed with the software R, ver. 4.0.1 [16].

\section{Results and Discussion}

The first fraction, analysed in the Petri dish experiment as limonene, contained d-limonene and carvone in 91.1\%:6.9\%. The second fraction was 53.3\% limonene and $45.4 \%$ carvone. The residue of the rectification process consisted of almost pure carvone: $99.8 \%$ and was analysed in the Petri dish experiment as carvone.

Germination of the tested species was affected to a different level by the tested caraway EO and its main compounds (Figure 1). Germination of spring wheat was mostly affected by caraway EO and carvone (ED50 0.006 and 0.008, respectively). Contrary, in the presence of limonene, all wheat seeds germinated, even at the highest dose of limonene (Figure 1a). The germination of wild oat was inhibited already by the lowest doses of caraway EO (ED50 0.001) and carvone (ED50 0.003). However, in the presence of limonene, the weed germinated well (Figure 1b). Chamomile was highly susceptible to the presence of caraway EO and carvone (ED50 $0.001 \mathrm{~g}$ for both) and less susceptible to the presence of limonene (ED50 0.003) (Figure 1c). The germination pattern of the studied species in the presence of caraway EO and its main compounds points to a strong herbicidal effect of the EO and carvone. The results are concurrent with other authors who underline the inhibiting effect of caraway EO and carvone on germination of weeds and crops $[9,17]$. 


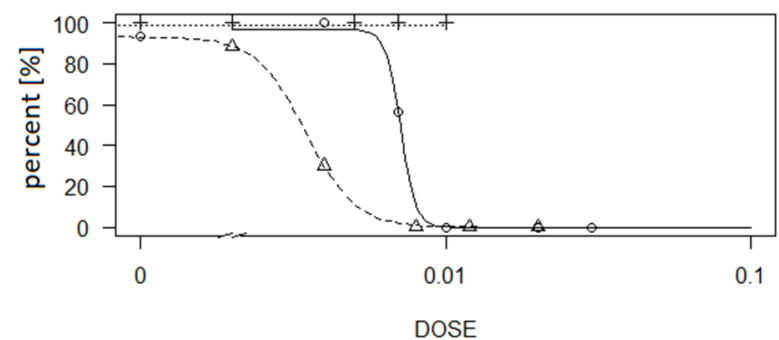

(a)

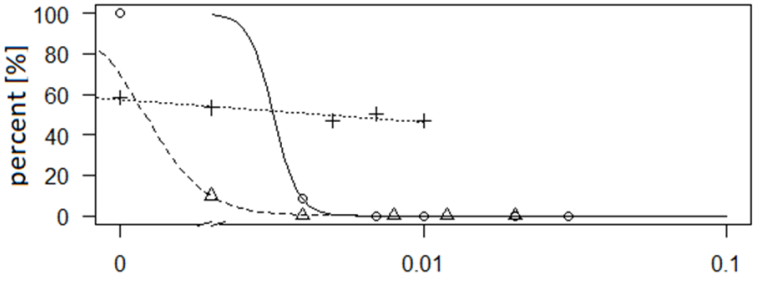

(b)

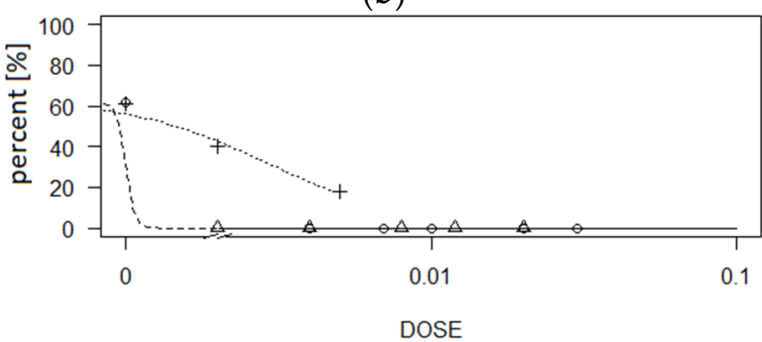

(c)

Figure 1. Dose-response curves of germination of spring wheat (a), wild oat (b) and chamomile (c) in the presence of different doses of caraway oil $-\Delta-$, carvone $-\bigcirc-$ and limonene $-\times-$.

The growth of seedlings of the tested species was highly affected by the caraway EO (Table 1), especially in chamomile. Only single seedlings of wild oat grew in the lowest doses of the EO, whereas growth of chamomile seedlings was completely inhibited even at the lowest oil dose. The very low values of ED50 also represent the susceptibility of the tested species to the caraway EO.

Table 1. The response of spring wheat, wild oats and chamomile seedlings to different doses of caraway oil (mean value \pm standard error).

\begin{tabular}{ccccccc}
\hline \multirow{2}{*}{ Dose [g] } & \multicolumn{3}{c}{ Shoot Length $[\mathrm{mm}]$} & \multicolumn{3}{c}{ Root Length $[\mathrm{mm}]$} \\
\cline { 2 - 7 } & Wheat & Wild Oat & Chamomile & Wheat & Wild Oat & Chamomile \\
\hline 0 & $57.8 \pm 0.66$ & $61.7 \pm 2.64$ & $11.3 \pm 0.7$ & $103 \pm 7.01$ & $52.9 \pm 17.2$ & $3.1 \pm 0.3$ \\
0.004 & $9.22 \pm 0.08$ & $1.31 \pm 0.35$ & $0 \pm 0$ & $12.3 \pm 0.25$ & $1.67 \pm 0.17$ & $0 \pm 0$ \\
0.007 & $2.49 \pm 1.99$ & $0 \pm 0$ & $0 \pm 0$ & $3.83 \pm 2.61$ & $0 \pm 0$ & $0 \pm 0$ \\
0.01 & $0 \pm 0$ & $0 \pm 0$ & $0 \pm 0$ & $0 \pm 0$ & $0 \pm 0$ & $0 \pm 0$ \\
0.02 & $0 \pm 0$ & $0 \pm 0$ & $0 \pm 0$ & $0 \pm 0$ & $0 \pm 0$ & $0 \pm 0$ \\
0.03 & $0 \pm 0$ & $0 \pm 0$ & $0 \pm 0$ & $0 \pm 0$ & $0 \pm 0$ & $0 \pm 0$ \\
ED50 & 0.002 & 0.002 & 0.001 & 0.001 & 0.002 & 0.001 \\
\hline
\end{tabular}

The seedlings' growth was inhibited by carvone even more than by the caraway EO (Table 2). Only a few seedlings of wheat grew in the presence of the lowest dose of that compound. The ED50 values of both shoot and root length were also very low. 
Table 2. The response of spring wheat, wild oats and chamomile seedlings to different doses of carvone (mean value \pm standard error).

\begin{tabular}{ccccccc}
\hline \multirow{2}{*}{ Dose [g] } & \multicolumn{3}{c}{ Shoot Length [mm] } & \multicolumn{3}{c}{ Root Length [mm] } \\
\cline { 2 - 7 } & Wheat & Wild Oat & Chamomile & Wheat & Wild Oat & Chamomile \\
\hline 0 & $57.8 \pm 0.66$ & $61.7 \pm 2.64$ & $11.3 \pm 0.7$ & $103 \pm 7.01$ & $52.9 \pm 17.2$ & $3.1 \pm 0.3$ \\
0.004 & $3.54 \pm 0.76$ & $0 \pm 0$ & $0 \pm 0$ & $5.81 \pm 1.07$ & $0.5 \pm 0.5$ & $0 \pm 0$ \\
0.007 & $0 \pm 0$ & $0 \pm 0$ & $0 \pm 0$ & $0 \pm 0$ & $0 \pm 0$ & $0 \pm 0$ \\
0.01 & $0 \pm 0$ & $0 \pm 0$ & $0 \pm 0$ & $0 \pm 0$ & $0 \pm 0$ & $0 \pm 0$ \\
0.02 & $0 \pm 0$ & $0 \pm 0$ & $0 \pm 0$ & $0 \pm 0$ & $0 \pm 0$ & $0 \pm 0$ \\
0.03 & $0 \pm 0$ & $0 \pm 0$ & $0 \pm 0$ & $0 \pm 0$ & $0 \pm 0$ & $0 \pm 0$ \\
ED50 & 0.001 & 0.001 & 0.001 & 0.001 & 0.001 & 0.001 \\
\hline
\end{tabular}

Contrary to the two other compounds, the seedlings of all the tested species germinated in the presence of limonene; however, the growth of wheat and wild oat seedlings was strongly inhibited, even by the lowest dose of the EO and its main compounds (Table 3). On the contrary, chamomile seedlings' growth in the presence of a majority of d-limonene doses was similar to the control, except that the elongation of roots was significantly inhibited at the highest dose. The ED50 values expressed the differences in susceptibilities between grasses and chamomile to d-limonene.

Table 3. The response of spring wheat, wild oats and chamomile seedlings to different doses of limonene (mean value \pm standard error). Statistical differences were indicated with different letters.

\begin{tabular}{ccccccc}
\hline \multirow{2}{*}{ Dose [g] } & \multicolumn{3}{c}{ Shoot Length [mm] } & \multicolumn{3}{c}{ Root Length [mm] } \\
\cline { 2 - 7 } & Wheat & Wild Oat & Chamomile & Wheat & Wild Oat & Chamomile \\
\hline 0 & $57.8 \pm 0.66 \mathrm{a}$ & $61.7 \pm 2.64 \mathrm{a}$ & $11.9 \pm 0.45 \mathrm{a}$ & $103 \pm 7.01 \mathrm{a}$ & $52.9 \pm 17.2 \mathrm{a}$ & $3.60 \pm 0.30 \mathrm{a}$ \\
0.004 & $10.5 \pm 0.37 \mathrm{~b}$ & $7.50 \pm 0.35 \mathrm{~b}$ & $11.8 \pm 0.35 \mathrm{a}$ & $14.6 \pm 0.34 \mathrm{~b}$ & $10.7 \pm 0.58 \mathrm{~b}$ & $2.81 \pm 0.21 \mathrm{a}$ \\
0.007 & $10.3 \pm 0.12 \mathrm{~b}$ & $7.64 \pm 0.29 \mathrm{~b}$ & $11.1 \pm 0.44 \mathrm{a}$ & $14.0 \pm 0.28 \mathrm{~b}$ & $12.4 \pm 0.37 \mathrm{~b}$ & $2.80 \pm 0.28 \mathrm{a}$ \\
0.01 & $10.0 \pm 0.41 \mathrm{~b}$ & $7.71 \pm 0.33 \mathrm{~b}$ & $8.73 \pm 0.22 \mathrm{a}$ & $15.1 \pm 0.09 \mathrm{~b}$ & $12.5 \pm 0.13 \mathrm{~b}$ & $2.32 \pm 0.23 \mathrm{a}$ \\
0.02 & $9.99 \pm 0.13 \mathrm{~b}$ & $8.26 \pm 0.20 \mathrm{~b}$ & $10.6 \pm 0.48 \mathrm{a}$ & $14.7 \pm 0.68 \mathrm{~b}$ & $10.4 \pm 0.77 \mathrm{~b}$ & $2.39 \pm 0.21 \mathrm{a}$ \\
0.03 & $9.45 \pm 0.25 \mathrm{~b}$ & $7.11 \pm 0.36 \mathrm{~b}$ & $8.85 \pm 1.01 \mathrm{a}$ & $14.2 \pm 0.18 \mathrm{~b}$ & $11.4 \pm 0.56 \mathrm{~b}$ & $1.92 \pm 0.43 \mathrm{~b}$ \\
ED50 & 0.001 & 0.001 & 0.07 & 0.001 & 0.001 & 0.02 \\
\hline
\end{tabular}

The herbicidal effect of caraway EO and carvone on the seedlings of wheat, wild oat and chamomile was strong in laboratory conditions. On the contrary, the effect of d-limonene was weaker, as seedlings were able to grow but were strongly inhibited. Interestingly, the inhibiting effect of d-limonene on elongation of shoots/roots was more visible in monocotyledonous wheat and wild oat than dicotyledonous chamomile. Studies by other authors show that weed and crop species display different susceptibilities to various essential oils and compounds $[9,18,19]$, which is a good selective effect for the future development of botanical herbicides.

\section{Conclusions}

In the laboratory conditions and with the doses applied, caraway EO and carvone inhibit germination and seedlings' growth of spring wheat, wild oat and chamomile. On the contrary, d-limonene does not affect the germination of wheat and wild oat but significantly inhibits the growth of their seedlings. D-limonene inhibits germination of chamomile in a dose-response manner, but the growth of seedlings is similar to that of control. In summary, d-limonene should be studied further for its potential selective properties.

Author Contributions: Conceptualization, A.S.; methodology, A.S. and A.W.-B.; investigation, B.J. and A.W.-B.; resources, A.S.; data curation, A.S.; writing-original draft preparation, B.J.; writingreview and editing, A.S. and A.W.-B.; visualization, A.S.; supervision, A.S. All authors have read and agreed to the published version of the manuscript. 
Funding: This research received no external funding.

Institutional Review Board Statement: Not applicable.

Informed Consent Statement: Not applicable.

Data Availability Statement: The data presented in this study are available on request from the corresponding author.

Conflicts of Interest: The authors declare no conflict of interest.

\section{References}

1. Farooq, M.; Jabran, K.; Cheema, Z.A.; Wahid, A.; Siddique, K.H. The role of allelopathy in agricultural pest management. Pest Manag. Sci. 2011, 67, 493-506. [CrossRef] [PubMed]

2. Macias, F.A.; Molinillo, J.M.; Varela, R.M.; Galindo, J.C. Allelopathy-A natural alternative for weed control. Pest Manag. Sci. 2007, 63, 327-348. [CrossRef]

3. Dudai, N.; Poljakoff-Mayber, A.; Mayer, A.M.; Putievsky, E.; Lerner, H.R. Essential oils as allelochemicals and their potential use as bioherbicides. J. Chem. Ecol. 1999, 25, 1079-1089. [CrossRef]

4. Synowiec, A.; Możdżeń, K.; Krajewska, A.; Landi, M.; Araniti, F. Carum carvi L. essential oil: A promising candidate for botanical herbicide against Echinochloa crus-galli (L.) P. Beauv. in maize cultivation. Ind. Crop. Prod. 2019, 140, 111652. [CrossRef]

5. Stokłosa, A.; Matraszek, R.; Isman, M.B.; Upadhyaya, M.K. Phytotoxic activity of clove oil, its constituents, and its modification by light intensity in broccoli and common lambsquarters (Chenopodium album). Weed Sci. 2012, 60, 607-611. [CrossRef]

6. Verdeguer, M.; Sánchez-Moreiras, A.M.; Araniti, F. Phytotoxic effects and mechanism of action of essential oils and terpenoids. Plants 2020, 9, 1571. [CrossRef] [PubMed]

7. Możdżeń, K.; Krajewska, A.; Bocianowski, J.; Jop, B.; Synowiec, A. Microencapsulated Caraway Essential Oil Affects Initial Growth of Maize Cultivars. Molecules 2021, 26, 5059. [CrossRef] [PubMed]

8. Blázquez, M.A.; Carbó, E. Control of Portulaca oleracea by boldo and lemon essential oils in different soils. Ind. Crop. Prod. 2015, 76, 515-521. [CrossRef]

9. Synowiec, A.; Kalemba, D.; Drozdek, E.; Bocianowski, J. Phytotoxic potential of essential oils from temperate climate plants against the germination of selected weeds and crops. J. Pest Sci. 2017, 90, 407-419. [CrossRef]

10. Ibáñez, M.D.; Blázquez, M.A. Phytotoxic effects of commercial essential oils on selected vegetable crops: Cucumber and tomato. Sustain. Chem. Pharm. 2020, 15, 100209. [CrossRef]

11. Ritz, C.; Streibig, J.C. Bioassay analysis using R. J. Stat. Softw. 2005, 12, 1-22. [CrossRef]

12. Zhou, S.; Han, C.; Zhang, C.; Kuchkarova, N.; Wei, C.; Zhang, C.; Shao, H. Allelopathic, phytotoxic, and insecticidal effects of Thymus proximus Serg. essential oil and its major constituents. Front. Plant Sci. 2021, 12, 689875. [CrossRef] [PubMed]

13. Aćimović, M.G.; Oljača, S.; Tešević, V.; Todosijević, M.M.; Djisalov, J.N. Evaluation of caraway essential oil from different production areas of Serbia. Hortic. Sci. 2014, 41, 122-130. [CrossRef]

14. Bainard, L.D.; Isman, M.B.; Upadhyaya, M.K. Phytotoxicity of clove oil and its primary constituent eugenol and the role of leaf epicuticular wax in the susceptibility to these essential oils. Weed Sci. 2006, 54, 833-837. [CrossRef]

15. Knezevic, S.Z.; Streibig, J.C.; Ritz, C. Utilizing R software package for dose-response studies: The concept and data analysis. Weed Technol. 2007, 21, 840-848. [CrossRef]

16. R Core Team. R: A Language and Environment for Statistical Computing; R Foundation for Statistical Computing: Vienna, Austria, 2020; Available online: https:/ / www.R-project.org/ (accessed on 15 March 2021).

17. Morcia, C.; Tumino, G.; Ghizzoni, R.; Terzi, V. Carvone (Mentha spicata L.) oils. In Essential Oils in Food Preservation, Flavor and Safety, 1st ed.; Preedy, V.R., Ed.; Academic Press: London, UK, 2016; pp. 309-316.

18. Cavalieri, A.; Caporali, F. Effects of essential oils of cinnamon, lavender and peppermint on germination of Mediterranean weeds. Allelopath. J. 2010, 25, 441-452.

19. Martino, L.D.; Mancini, E.; Almeida, L.F.R.D.; Feo, V.D. The antigerminative activity of twenty-seven monoterpenes. Molecules 2010, 15, 6630-6637. [CrossRef] [PubMed] 